\title{
Advantages and disadvantages from enforcing emission restrictions within emission control areas
}

\author{
Maxim A. Dulebenets \\ Department of Civil and Environmental Engineering, \\ Florida A\&M University-Florida State University, Tallahassee, \\ Florida, USA
}

\begin{abstract}
Purpose - Emissions produced by oceangoing vessels not only negatively affect the environment but also may deteriorate health of living organisms. Several regulations were released by the International Maritime Organization (IMO) to alleviate negative externalities from maritime transportation. Certain polluted areas were designated as "Emission Control Areas" (ECAs). However, IMO did not enforce any restrictions on the actual quantity of emissions that could be produced within ECAs. This paper aims to perform a comprehensive assessment of advantages and disadvantages from introducing restrictions on the emissions produced within ECAs. Two mixed-integer non-linear mathematical programs are presented to model the existing IMO regulations and an alternative policy, which along with the established IMO requirements also enforces restrictions on the quantity of emissions produced within ECAs. A set of linearization techniques are applied to linearize both models, which are further solved using the dynamic secant approximation procedure. Numerical experiments demonstrate that introduction of emission restrictions within ECAs can significantly reduce pollution levels but may incur increasing route service cost for the liner shipping company.

Design/methodology/approach - Two mixed-integer non-linear mathematical programs are presented to model the existing IMO regulations and an alternative policy, which along with the established IMO requirements also enforces restrictions on the quantity of emissions produced within ECAs. A set of linearization techniques are applied to linearize both models, which are further solved using the dynamic secant approximation procedure.

Findings - Numerical experiments were conducted for the French Asia Line 3 route, served by CMA CGM liner shipping company and passing through ECAs with sulfur oxide control. It was found that introduction of emission restrictions reduced the quantity of sulfur dioxide emissions produced by 40.4 per cent. In the meantime, emission restrictions required the liner shipping company to decrease the vessel sailing speed not only at voyage legs within ECAs but also at the adjacent voyage legs, which increased the total vessel turnaround time and in turn increased the total route service cost by 7.8 per cent.
\end{abstract}

(C) Pacific Star Group Education Foundation

This work was partially supported by the Department of Civil Engineering at the University of Memphis (Memphis, TN) and the Department of Civil and Environmental Engineering at the Florida A\&M University - Florida State University (Tallahassee, FL). Any opinions, findings, conclusions, or recommendations are those of the author and do not necessarily reflect the views of the aforementioned organizations.

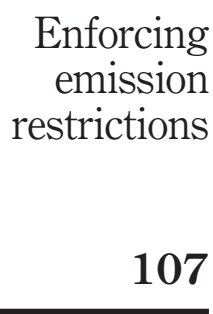

Enforcing . 
MABR

1,2

108

Research limitations/implications - This study does not capture uncertainty in liner shipping operations.

Practical implications - The developed mathematical model can serve as an efficient practical tool for liner shipping companies in developing green vessel schedules, enhancing energy efficiency and improving environmental sustainability.

Originality/value - Researchers and practitioners seek for new mathematical models and environmental policies that may alleviate pollution from oceangoing vessels and improve energy efficiency. This study proposes two novel mathematical models for the green vessel scheduling problem in a liner shipping route with ECAs. The first model is based on the existing IMO regulations, whereas the second one along with the established IMO requirements enforces emission restrictions within ECAs. Extensive numerical experiments are performed to assess advantages and disadvantages from introducing emission restrictions within ECAs.

Keywords Environmental regulations, Environmental sustainability, Emission control areas, Emission restrictions, Green vessel scheduling, Marine transportation

Paper type Research paper

\section{Introduction}

Maritime transportation plays a vital role for international trade. The United Nations Conference on Trade and Development indicates that the international seaborne trade increased to 9.8 billion tons in 2014, as compared to 9.5 billion tons reported in 2013 (UNCTAD, 2015). The containerized cargo increased by 5.6 per cent in tonnage from 2013 to 2014, whereas major bulk and dry cargos increased by 6.5 and 2.4 per cent, respectively (UNCTAD, 2015). In the meantime, maritime transportation is a source of emissions, which may negatively affect both the environment and health of living organisms. Generally, emissions from oceangoing vessels can be categorized in two classes: greenhouse gases and non-greenhouse gases. Greenhouse gases cause changes in climate and are mainly represented with the following pollutants: carbon dioxide $\mathrm{CO}_{2}$, nitrous oxide $-\mathrm{N}_{2} \mathrm{O}$ and methane $-\mathrm{CH}_{4}$ (Psaraftis and Kontovas, 2013). International Maritime Organization (IMO) underlines that approximately 2.2 per cent of the overall emitted $\mathrm{CO}_{2}$ in the world is produced by the maritime sector (IMO, 2014). Non-greenhouse gases may damage not only the environment (by causing warming and cooling effects, deforestation, acid rain, etc.) but also health of living organisms. Non-greenhouse gases are mainly represented with the following pollutants: nitrogen oxides $-\mathrm{NO}_{\mathrm{x}}$ and sulfur oxides $-\mathrm{SO}_{\mathrm{x}}$ (Psaraftis and Kontovas, 2013).

Over the past years, IMO released a number of regulations to protect the environment and living organisms and reduce emissions from maritime transportation. To date, IMO designated four distinct "Emission Control Areas" (ECAs), including the following (IMO, 2016a):

(1) Baltic Sea area with established restrictions on $\mathrm{SO}_{\mathrm{x}}$ (effective since 2005);

(2) North Sea area with established restrictions on $\mathrm{SO}_{\mathrm{x}}$ (effective since 2005);

(3) North American area with established restrictions on $\mathrm{NO}_{\mathrm{x}}, \mathrm{SO}_{\mathrm{x}}$ and particulate matter (effective since 2012); and

(4) USA Caribbean Sea area with established restrictions on $\mathrm{NO}_{\mathrm{x}}, \mathrm{SO}_{\mathrm{x}}$ and particulate matter (effective since 2014). 
IMO also plans to designate Norway, Japan and Mediterranean as ECAs (Marine Urea, 2014). The $\mathrm{SO}_{\mathrm{x}}$ emissions are currently regulated by setting restrictions on the percentage of sulfur in the fuel. According to the IMO regulations 14.1 and 14.4 (IMO, 2016a), the percentage of fuel sulfur should not exceed 3.50 per cent $\mathrm{m} / \mathrm{m}$ after January 01, 2012, and 0.50 per cent $\mathrm{m} / \mathrm{m}$ after January 01, 2020, for vessels sailing outside ECAs. The percentage of fuel sulfur is limited to 1.00 per cent $\mathrm{m} / \mathrm{m}$ after July 01,2010 , and to 0.10 per cent $\mathrm{m} / \mathrm{m}$ after January 01,2015 , for vessels sailing within ECAs.

The $\mathrm{NO}_{\mathrm{x}}$ emissions are regulated by establishing requirements on diesel engines depending on their maximum operating speed (DieselNet, 2016). There are a total of three types of tier limits varying by the quantity of allowable $\mathrm{NO}_{\mathrm{x}}$ emissions produced. The strictest Tier III limit is applied to vessel diesel engines within $\mathrm{NO}_{\mathrm{x}}$ ECAs. Regarding the greenhouse gas regulations, IMO introduced a new chapter with amendments to MARPOL Annex VI, titled as "Regulations on energy efficiency for ships", in 2011 (IMO, 2016b). The main objective of those amendments was to enforce requirements against producing greenhouse gas emissions. According to those mandatory measures, the vessels are required to attain a specific "Energy Efficiency Design Index" (which is estimated based on vessel technical characteristics and fuel used) and implement a "Ship Energy Efficiency Management Plan" (IMO, 2016b). Moreover, The European Union (2010) established a quite challenging goal of decreasing greenhouse gas emissions by 60 per cent by 2050 as compared to the greenhouse gas emissions produced in 2010.

Taking into consideration increasing volumes of the international trade and new environmental regulations in maritime transportation, liner shipping companies have to ensure efficiency of their operations and, in the meantime, comply with the emission restrictions established by competent organizations. The existing environmental regulations, enforced by IMO, do not pose any limits on the actual quantity of emissions produced by vessels. This paper proposes two mixed-integer non-linear mathematical models to assess the effect of introducing emission restrictions within ECAs. The objective of models is to minimize the total route service cost. Both mathematical models are linearized and then solved using a dynamic secant approximation procedure. Extensive numerical experiments are performed for the French Asia Line 3 route, served by CMA CGM liner shipping company and passing through $\mathrm{SO}_{\mathrm{x}} \mathrm{ECAs}$. The rest of the manuscript is organized as follows. Section 2 presents an up-to-date literature review with focus on environmental considerations in vessel scheduling, and Section 3 provides the problem description. Section 4 presents two mathematical models for the green vessel scheduling problem in a liner shipping route with ECAs, and Section 5 describes the solution approach. Section 6 presents a number of the computational experiments that were conducted in this study to evaluate performance of the adopted solution approach and assess the effect of introducing emission restrictions within ECAs. Section 7 summarizes findings and provides conclusions and future research extensions.

\section{Literature review}

The problem of vessel scheduling in liner shipping receives a constant attention from the research community. The vessel scheduling problem is a tactical-level decision problem, which aims to determine the vessel sailing speeds at voyage legs of the liner shipping route, arrival times at ports of call of the given port rotation, vessel handling and departure times (Meng et al., 2014). The literature review presented herein will focus on environmental considerations in vessel scheduling. The collected studies can be classified in two groups.

\section{Enforcing emission \\ restrictions}


MABR

1,2

\section{0}

The first group of studies presents either theoretical or analytical research and discusses environmental concerns in vessel scheduling but does not provide any mathematical models that may capture those environmental concerns. The second group of studies presents models that can be used by liner shipping companies in design of green vessel schedules. The review of both study groups is presented next.

\subsection{Environmental concerns in vessel scheduling}

Eyring et al. (2010) discussed the negative externalities which could be caused by the emissions produced from vessels. It was underlined that vessel emissions might damage not only the environment but also living organisms. Miola and Ciuffo (2011) performed a critical review of methods that could be used in calculating vessel emissions. The study categorized all the methods based on the liner shipping route and vessel technical characteristics. Psaraftis and Kontovas (2013) conducted a survey of the existing vessel speed models. It was highlighted that the emissions produced by oceangoing vessels were highly dependent on the vessel sailing speed. Cullinane and Bergqvist (2014) mentioned that IMO could consider introduction of new ECAs in densely populated regions because of increasing pollution levels. Moreover, stricter regulations on $\mathrm{SO}_{\mathrm{x}}$ and $\mathrm{NO}_{\mathrm{x}}$ emissions might be enforced in the future. Nevertheless, new ECAs would cause only limited modal shift effects.

Several studies focused primarily on the analysis of greenhouse gas emissions and $\mathrm{CO}_{2}$ emissions from vessels. Psaraftis and Kontovas (2009) conducted a comprehensive analysis of the world $\mathrm{CO}_{2}$ emissions produced by the commercial vessel fleet. Findings indicated that vessel type and size significantly influenced the quantity of emissions produced. Heitmann and Khalilian (2011) studied different $\mathrm{CO}_{2}$ emission allocation options and considered the following factors: possibility of implementation, effectiveness, burden sharing and fairness. Results from the analysis suggested that emission allocation must be conducted on basis of the operating company. Psaraftis (2012) highlighted variability of market-based measures that could be used by IMO to decrease greenhouse gas emissions. Furthermore, the IMO decision was highly dependent on the agreement between developing and developed countries.

Many of the collected articles discussed application of the "slow steaming" concept to reduce $\mathrm{CO}_{2}$ emissions. Corbett et al. (2009) assessed efficiency of slow steaming in reduction of emissions from vessels. Findings indicated that fuel tax of $\$ 150$ per ton might decrease $\mathrm{CO}_{2}$ emissions by up to 30 per cent. Furthermore, slow steaming was found to be an effective alternative in reducing $\mathrm{CO}_{2}$ emissions. Psaraftis and Kontovas (2010) highlighted that slow steaming allowed decreasing $\mathrm{CO}_{2}$ emissions but, in the meantime, might cause increase in the cargo transit time, which would further require deployment of more vessels at the given liner shipping route to guarantee the agreed service frequency at ports. Cariou (2011) also underlined efficiency of slow steaming in emission reduction. The study mentioned that future implementation of slow steaming strategy was highly dependent on freight rates and bunker consumption costs. Lindstad et al. (2011) performed the analysis of the slow steaming concept and how it could affect the quantity of emissions produced by vessels. It was found that in case of zero abatement cost, representing the cost of emissions, slow steaming might yield 28 per cent reduction in $\mathrm{CO}_{2}$ emissions.

Cariou and Cheaitou (2012) conducted a study to determine if introduction of a speed limit would be advantageous in decreasing $\mathrm{CO}_{2}$ emissions. The analysis was performed 
for two transatlantic services. Findings indicated that a bunker levy would be a more efficient alternative as compared to the speed limit. Chang and Wang (2014) analyzed various scenarios to identify the optimal reduction in the vessel sailing speed. Advantages from the speed reduction were estimated based on the reduction in $\mathrm{CO}_{2}$ emissions and associated bunker consumption costs. It was found that the vessel sailing speed reduction would be the most beneficial for scenarios with low charter and high bunker consumption costs. Psaraftis and Kontovas (2014) performed the evaluation of various factors which could influence the decision on the vessel sailing speed. Results from the analysis indicated that freight rates, inventory costs, payload and bunker price mostly affected selection of the vessel sailing speed.

\subsection{Green vessel scheduling models}

Many of published-to-date vessel scheduling models captured various operational aspects; however, only a few of them focused on the environmental concerns (Mansouri et al., 2015). Qi and Song (2012) studied the vessel scheduling problem with uncertainty in port times without explicitly modeling vessel emissions. However, the authors highlighted that emissions from oceangoing vessels could be decreased by optimizing the vessel schedule. Kontovas (2014) discussed some important aspects that had to be considered in green vessel scheduling and proposed a generic mathematical formulation for the green vessel scheduling problem. A number of alternatives for modeling vessel emissions were presented. Dulebenets et al. (2015a) developed a novel mathematical formulation for the green vessel scheduling problem, minimizing the total route service cost. The model imposed constraints on the emissions produced at each voyage leg of the liner shipping route. However, the study did not model ECAs. Fagerholt and Psaraftis (2015) and Fagerholt et al. (2015) studied the problem of vessel routing and sailing speed optimization within ECAs but did not explicitly model the service of vessels at ports of call. Song et al. (2015) developed an evolutionary algorithm to solve a stochastic multi-objective vessel scheduling problem, considering uncertainty in port times. The following three objectives were minimized:

(1) the annual total vessel operational costs;

(2) the average schedule unreliability; and

(3) the annual total $\mathrm{CO}_{2}$ emissions from all the vessels serving a given liner shipping route.

\subsection{Contribution}

The overview of the literature suggests that green vessel scheduling is an evolving area of research and receives an increasing attention from the community. Researchers and practitioners seek for new mathematical models and environmental policies that may alleviate pollution from oceangoing vessels and improve energy efficiency. This study proposes two novel mathematical models for the green vessel scheduling problem in a liner shipping route with ECAs. The first model is based on the existing IMO regulations, whereas the second one along with the established IMO requirements enforces emission restrictions within ECAs. Extensive numerical experiments are performed to assess advantages and disadvantages from introducing emission restrictions within ECAs.
Enforcing emission restrictions 
MABR

1,2

112

\section{Problem description}

This study considers a typical liner shipping route, which includes $I=\{1, \ldots, n\}$ ports of call. The port rotation (i.e. sequence of visited ports) is assumed to be known, as this decision is usually made by the liner shipping company at the strategic level (Meng et al., 2014). Each port of call is visited once; however, the proposed methodology can be also used for liner shipping routes, where a given port of call is visited more than once. In the latter situation (i.e. when a given port of call is visited more than once), an additional node will be added to the graph, which represents the port rotation, to account for the second visit to the same port. For example, the liner shipping route, presented in Figure 1(a), includes a total of four ports. Ports 1 and 2 are visited twice; hence, two additional nodes $1^{\prime}$ and $2^{\prime}$ are introduced to the graph, and the total number of ports to be visited will be $|I|=$ $4+2=6$ [Figure 1(b)]

A vessel sails between two consequent ports $i$ and $i+1$ along leg $i$. It is assumed that certain legs of a liner shipping route pass through ECAs. The subset of voyage legs, passing through ECAs, will be referred to as $I^{*}$, whereas the rest of voyage legs (passing outside ECAs) will belong to subset $I^{0}$. Note that $I^{0} \cup I^{*}=I, I^{0} \cap I^{*}=\varnothing$. The liner shipping company should provide service with a certain frequency at each port of call (typically weekly or bi-weekly service). The terminal operator at each port establishes a specific arrival time window - TW $\left[t w_{i}^{s}-\right.$ start of TW at port $i, t w_{i}^{e}$ - end of TW at port i], during which a vessel should arrive at the given port of call. Duration of a TW may vary from one to three days depending on the port (OOCL, 2016). The service of a vessel is assumed to start upon its arrival. If a vessel arrives at port $i$ prior to the start of TW, it will be waiting for service at a dedicated area. A monetary penalty will be imposed on the liner shipping company if a vessel arrives after the end of TW (Dulebenets et al., 2015a). The container demand (measured in TEUs) at each port of call is assumed to be known (Meng et al., 2014).

\subsection{Vessel service at ports}

This study assumes that a liner shipping company has contractual agreements with marine container terminal operators. Based on those agreements, each marine container terminal operator is able to offer a set of handling rates $S_{i}=\left\{1, \ldots, h_{i}\right\} \forall i \in I$ to the liner shipping company. Each handling rate has a corresponding handling productivity $d_{i s} \forall i \in I, s \in S_{i}$, measured in TEUs per hour. Vessel handling time $p_{i s} \forall i \in I, s \in S_{i}$ (in hours) is estimated based on the container demand at a given port and the handling productivity requested. Note that a handling rate, which has a higher handling productivity, will reduce the vessel handling time at a given port of call but will increase the port handling cost for the liner shipping company.

Figure 1.

Schematic representation of a liner shipping route

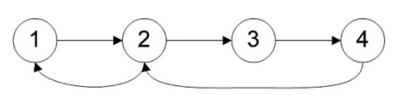

(a)

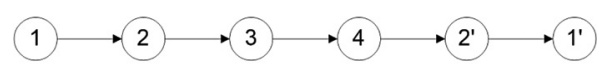

(b) 


\subsection{Bunker consumption}

The vessel fleet, serving a given liner shipping route, is assumed to be homogeneous (i.e. all vessels in the fleet have the same/similar technical characteristics). The latter practice has been widely adopted in the vessel scheduling literature (Wang and Meng, 2012a, 2012b, 2012c; Wang et al., 2013, 2014). The bunker consumption is assumed to be proportional to the vessel sailing speed and can be computed from the following equation (Du et al., 2011; Wang and Meng, 2012b):

\section{Enforcing emission restrictions}

$$
q(\bar{v})=q\left(v^{*}\right)\left(\frac{\bar{v}}{v^{*}}\right)^{\alpha}=\gamma(\bar{v})^{\alpha}
$$

Where:

$q(\bar{v})=$ daily bunker consumption by vessel (tons of fuel/day);

$\bar{v} \quad=$ average daily vessel sailing speed (knots);

$q\left(v^{*}\right)=$ daily bunker consumption by vessel when sailing at the designed speed (tons of fuel/day);

$v^{*} \quad=$ design vessel sailing speed (knots); and

$\alpha, \gamma=$ bunker consumption coefficients.

Technically, to determine the values of bunker consumption coefficients $\alpha$ and $\gamma$, the regression analysis should be performed for each vessel in the fleet (Du et al., 2011; Wang and Meng, 2012b). This study will use the most common values of the bunker consumption coefficients revealed in the literature (Psaraftis and Kontovas, 2013; Wang and Meng, 2012b): $\alpha=3$ and $\gamma=0.012$. Once the liner shipping company makes a decision on a vessel sailing speed between consequent ports of call, it will remain constant. The factors that may influence the vessel speed throughout the voyage (e.g. weather, height of waves, speed of wind, etc.) are not modeled. The bunker consumption by auxiliary engines will be included as a part of the weekly vessel operational cost. The bunker consumption $f\left(v_{i}\right)$ can be computed per nautical mile at leg $i$ using the following equation:

$$
f\left(v_{i}\right)=q\left(v_{i}\right)\left(\frac{t_{i}}{24}\right) \frac{1}{l_{i}}=\gamma\left(v_{i}\right)^{\alpha} \frac{l_{i}}{24 v_{i}} \frac{1}{l_{i}}=\frac{\gamma\left(v_{i}\right)^{\alpha-1}}{24} \forall i \in I
$$

Where:

$l_{i}=$ length of voyage leg $i$, which connects ports $i$ and $i+1$ (nmi); and

$t_{i}=$ sailing time between ports $i$ and $i+1$ (hours).

\subsection{Inventory cost}

In the design of the vessel schedule, the liner shipping company has to consider the inventory cost, which is proportional to the total transit time. The total inventory cost of containers, which are transported at the given liner shipping route, can be estimated using the following equation (Wang et al., 2014):

$$
I C=\mu \sum_{i \in I} t_{i} N C T_{i}
$$


MABR

1,2

Where:

IC = total inventory cost (USD);

$\mu \quad=$ unit inventory cost (USD per TEU per hour); and

$N C T_{i}=$ quantity of containers transported at leg $i$ (TEUs).

\subsection{Existing International Maritime Organization regulations}

The existing IMO regulation requires that the sulfur content in the fuel cannot exceed 0.1 per cent when passing through $\mathrm{SO}_{\mathrm{x}} \mathrm{ECAs}$ (IMO, 2016a). This study assumes that the vessels use Marine Gas Oil (MGO) with sulfur content $P_{i}=0.1 \% \forall i \in I^{*}$ at voyage legs passing through ECAs. At the rest of voyage legs, the vessels use Heavy Fuel Oil (HFO) with sulfur content $P_{i}=3.5 \% \forall i \in I^{0}$. Furthermore, the diesel engines of vessels, deployed at the given liner shipping route, comply with Tier III limits in case of ECAs with restrictions on $\mathrm{NO}_{\mathrm{x}}$ emissions. The latter assumption can be relaxed for liner shipping routes passing though ECAs with $\mathrm{SO}_{\mathrm{x}}$ control only (e.g. Baltic Sea and North Sea).

\subsection{Emission restrictions}

The scope of this study includes modeling of the environmental policy, which not only complies with the existing IMO regulations but also enforces restrictions on the actual quantity of emissions produced within $\mathrm{ECAs} . \mathrm{NO}_{\mathrm{x}}$ emissions are regulated by enforcing requirements on diesel engines. Hence, given configuration of a diesel engine and its maximum operating speed, the vessel will not be able produce more $\mathrm{NO}_{\mathrm{x}}$ emissions than established by the IMO limit. As for sulfur emissions (i.e. $\mathrm{SO}_{\mathrm{x}}$, sulfur dioxide $\left[\mathrm{SO}_{2}\right]$ and particulate matter), they are regulated by enforcing restrictions on the type of fuel within ECAs. Use of low sulfur fuel will reduce the quantity of sulfur emissions, but the total quantity still can be substantial when vessels are sailing at high speeds through ECAs. $\mathrm{As}_{\mathrm{SO}_{2}}$ emissions comprise 98 per cent of sulfur emissions (Kontovas 2014), this study will model restrictions on $\mathrm{SO}_{2}$ emissions only.

\subsection{Emission estimation}

The quantity of $\mathrm{SO}_{2}$ emissions is significantly affected with the quantity of sulfur in the fuel. $\mathrm{SO}_{2}$ emissions (in tons) at leg $i$ can be computed based on the percentage of sulfur in the fuel $\left(P_{i} \forall i \in I\right.$, per cent) and factor 0.02 , which indicates that only 2 per cent of sulfur will react with oxygen and produce $\mathrm{SO}_{2}$ emissions (Kontovas 2014):

$$
S O_{2 i}=0.02 P_{i} f\left(v_{i}\right) l_{i} \forall i \in I
$$

\subsection{Decisions}

The problem studied herein can be categorized as a tactical-level problem and will be referred to as the green vessel scheduling problem in a liner shipping route with ECAs. The liner shipping company has to determine the following in this problem:

- the quantity of vessels required to provide the agreed service frequency at each port of the port rotation (assumed to be one week);

- the vessel sailing speed between consequent ports of call;

- one of the available handling rates at each port; 
- the waiting time at each port, belonging to the liner shipping route; and

- the hours of vessel late arrival at each port of call.

Enforcing emission

The above mentioned decisions that have to be made by the liner shipping company in restrictions this problem are interrelated. Before deciding on a vessel sailing speed at a given voyage leg, the liner shipping company should consider the limits on vessel sailing speed $\left(v^{\min } \leq v_{i} \leq v^{\max } \forall i \in I\right.$ ), bunker consumption, inventory costs, vessel emissions and emission restrictions within ECAs. The liner shipping company may use the concept of slow steaming to reduce bunker consumption and associated emissions. The latter will increase the total transit time of containers and will require deployment of more vessels to ensure that the weekly service is provided at each port of the port rotation. In the meantime, the liner shipping company must account for the limit on quantity of vessels $\left(q \leq q^{m a x}\right)$ allocated for service of the given liner shipping route. Availability of multiple handling rates at ports of call allows the liner shipping company to consider different alternatives between sailing and port handling times (e.g. selection of a handling rate with a higher productivity will decrease the handling time at a given port of call and will allow sailing at a lower speed to the next port of the port rotation).

\section{Mathematical models}

This section presents two mathematical models: the green vessel scheduling problem, which enforces the existing IMO regulations and ensures that a low-sulfur fuel is used at voyage legs passing through ECAs (will be referred to as GVSP1), and the green vessel scheduling problem, which imposes the requirements not only on the fuel type within ECAs but also on the quantity of emissions produced (will be referred to as $G \boldsymbol{V S P} 2$ ).

\subsection{Nomenclature}

4.1.1 Sets

$I=\{1, \ldots, n\} \quad=$ set of ports to be visited

$S_{i}=\left\{1, \ldots, h_{i}\right\} \forall i \in I=$ set of handling rates available to the liner shipping company at port $i$

\subsubsection{Decision variables}

$v_{i} \forall i \in I \quad=$ vessel sailing speed at voyage leg $i$ (knots)

$x_{i s} \forall i \in I, s \in S_{i}=1$ if handling rate $s$ is selected at port $i$ ( 0 otherwise)

\subsubsection{Auxiliary variables}

$q \quad=$ quantity of vessels assigned to the given liner shipping route (vessels)

$t_{i}^{a} \forall i \in I \quad=$ arrival time at port $i$ (hours)

$t_{i}^{d} \forall i \in I \quad=$ departure time from port $i$ (hours)

$w t_{i} \forall i \in I \quad=$ waiting time of a vessel at port $i$ (hours)

$t_{i} \forall i \in I \quad=$ sailing time of a vessel at voyage leg $i$ (hours)

$f\left(v_{i}\right) \forall i \in I=$ total bunker consumption by a vessel at voyage leg $i$ (tons of fuel $/ \mathrm{nmi}$ )

$l t_{i} \forall i \in I \quad=$ vessel late arrival at port $i$ (hours)

\subsubsection{Parameters}

$\beta_{i} \forall i \in I \quad=$ unit bunker cost when sailing at voyage leg $i$ (USD/ton) 
MABR

1,2

$c^{O C} \quad=$ vessel weekly operational cost $(\mathrm{USD} / \mathrm{week})$

$c_{i}^{L T} \forall i \in I \quad=$ delayed arrival penalty at port $i(\mathrm{USD} / \mathrm{h})$

$\mu \quad=$ unit inventory cost (USD per TEU per h)

$l_{i} \forall i \in I \quad=$ length of voyage leg $i(\mathrm{nmi})$

$N C T_{i} \forall i \in I \quad=$ quantity of containers transported at voyage leg $i$ (TEUs)

$v^{\min } \quad=$ minimum sailing speed of a vessel (knots)

$v^{\max } \quad=$ maximum sailing speed of a vessel (knots)

$q^{\max }$

$t w_{i}^{s} \forall i \in I \quad=$ start of TW at port $i$ (hours)

$t w_{i}^{e} \forall i \in I \quad=$ end of TW at port $i$ (hours)

$t c_{i s} \forall i \in I, s \in S_{i}=$ handling cost of a vessel at port $i$ under handling rate $s$ (USD)

$p_{i s} \forall i \in I, s \in S_{i}=$ handling time of a vessel at port $i$ under handling rate $s$ (hours)

\subsection{The green vessel scheduling problem with the existing International Maritime}

Organization regulations

The mixed-integer non-linear green vessel scheduling problem GVSP1 can be formulated as follows:

\section{GVSP1}

$$
\min \left[c^{O C} q+\sum_{i \in I} \beta_{i} l_{i} f\left(v_{i}\right)+\sum_{i \in I} \sum_{s \in S_{i}} t c_{i s} x_{i s}+\sum_{i \in I} c_{i}^{L T} l t_{i}+\mu \sum_{i \in I} t_{i} N C T_{i}\right]
$$

subject to:

$$
\begin{gathered}
\sum_{s \in S_{i}} x_{i s}=1 \forall i \in I \\
t_{i}=\frac{l_{i}}{v_{i}} \forall i \in I \\
t_{i}^{a} \geq t w_{i}^{s} \forall i \in I \\
w t_{i} \geq t w_{i+1}^{s}-t_{i}^{a}-\sum_{s \in S_{i}}\left(p_{i s} x_{i s}\right)-t_{i} \forall i \in I, i<|I| \\
w t_{i} \geq t w_{1}^{s}-t_{i}^{a}-\sum_{s \in S_{i}}\left(p_{i s} x_{i s}\right)-t_{i}+168 q \forall i \in I, i=|I| \\
t_{i}^{d}=t_{i}^{a}+\sum_{s \in S_{i}}\left(p_{i s} x_{i s}\right)+w t_{i} \forall i \in I \\
l t_{i} \geq t_{i}^{a}-t w_{i}^{e} \forall i \in I \\
t_{i+1}^{a}=t_{i}^{d}+t_{i} \forall i \in I, i<|I|
\end{gathered}
$$




$$
\begin{gathered}
t_{1}^{a}=t_{i}^{d}+t_{i}-168 q \forall i \in I, i=|I| \\
168 q \geq \sum_{i \in I} t_{i}+\sum_{i \in I} \sum_{s \in S_{i}}\left(p_{i s} x_{i s}\right)+\sum_{i \in I} w t_{i} \\
q \leq q^{\max } \\
v^{\min } \leq v_{i} \leq v^{\max } \forall i \in I \\
x_{i s} \in\{0,1\} \forall i \in I, s \in S_{i} \\
q, q^{\max }, N C T_{i} \in N \forall i \in I
\end{gathered}
$$

and

$$
v_{i}, t_{i}^{a}, t_{i}^{d}, w t_{i}, t_{i}, f\left(v_{i}\right), l t_{i}, \beta_{i}, c^{O C}, c_{i}^{L T}, \mu, l_{i}, v^{\min }, v^{\max }, t w_{i}^{s}, t w_{i}^{e}, t c_{i s}, p_{i s} \in R^{+} \forall i \in I, s \in S_{i}
$$

In $G V S P 1$, the liner shipping company aims to minimize the total route service cost (5), which consists of five components:

(1) total vessel weekly operational cost;

(2) total bunker consumption cost;

(3) total port handling cost;

(4) total late arrival penalty; and

(5) total inventory cost.

Note that the unit bunker $\operatorname{cost} \beta_{i}$ varies at voyage legs. A more expensive low-sulfur MGO is used at voyage legs passing through ECAs $\left(\beta_{i}=\beta_{M G O} \forall i \in I^{*}\right.$, where $\beta_{M G O}$ - the unit MGO cost), whereas HFO is used at the rest of the voyage legs $\left(\beta_{i}=\beta_{H F O} \forall i \in I^{0}\right.$, where $\beta_{H F O}$ - the unit HFO cost). Constraints set (6) ensures that only one handling rate should be selected by the liner shipping company at each port of the port rotation. Constraints set (7) estimates a sailing time of vessel between consequent ports $i$ and $i+1$. Constraints set (8) indicates that a vessel cannot be served at port $i$ before the start of TW. Constraints sets (9) and (10) calculate waiting time of a vessel at port $i$. Constraints set (11) computes departure time of a vessel from port $i$. Constraints set (12) calculates late arrival hours of a vessel at port $i$. Constraints sets (13) and (14) estimate arrival time of a vessel at the next port of the port rotation. Constraints set (15) indicates that the weekly service at each port of call should be met (168 represents the total number of hours in a week). The right-hand-side of the inequality calculates the total turnaround time of a vessel at the given liner shipping route and includes three components:

(1) the total sailing time;

(2) the total port handling time; and

(3) the total port waiting time. 
MABR

1,2

Constraints set (16) indicates that the quantity of vessels assigned for service of the given liner shipping route cannot exceed the quantity of available vessels. Constraints set (17) establishes bounds on sailing speed of a vessel at voyage leg $i$. Constraints (18)-(20) define ranges of variables and parameters.

\subsection{The green vessel scheduling problem with emission restrictions}

Denote $\mathrm{RSO}_{2}$ as the restriction on production of $\mathrm{SO}_{2}$ emissions (tons) at voyage leg $i$. Then, the mixed-integer non-linear green vessel scheduling problem $G \boldsymbol{V S P} 2$ that accounts for the requirements not only on the fuel type within ECAs but also on the quantity of $\mathrm{SO}_{2}$ emissions produced can be formulated as follows:

\section{GVSP2}

$$
\min \left[c^{O C} q+\sum_{i \in I} \beta_{i} l_{i} f\left(v_{i}\right)+\sum_{i \in I} \sum_{s \in S_{i}} t c_{i s} x_{i s}+\sum_{i \in I} c_{i}^{L T} l t_{i}+\mu \sum_{i \in I} t_{i} N C T_{i}\right]
$$

subject to:

Constraint sets (6)-(20).

$$
S O_{2 i}=0.02 P_{i} f\left(v_{i}\right) l_{i} \forall i \in I
$$

and

$$
S O_{2 i} \leq R S O_{2 i} \forall i \in I^{*}
$$

In $G V S P 2$, the liner shipping company aims to minimize the total route service cost (21). Constraints set (22) estimates $\mathrm{SO}_{2}$ emissions at voyage leg $i$. Constraints set (23) indicates that $\mathrm{SO}_{2}$ emissions at voyage leg $i$ cannot exceed the established restrictions.

\section{Solution approach}

GVSP1 is a non-linear mathematical model due to: 1) objective function (5); and 2) constraints set (7). Non-linearity of GVSP2 stems from: 1) objective function (21); and 2) constraints sets (7) and (22). This section discusses how both models can be reformulated as liner problems. Replacing of vessel sailing speed $v_{i}$ with its reciprocal $y_{i}=1 / v_{i}$ will linearize constraints set (7). Denote $G(y)$ as the bunker consumption function estimated based on vessel sailing speed reciprocal $y$. The non-linear bunker consumption function $G(y)$ can be linearized using its piecewise linear secant approximation $\overline{G_{m}}(y)$, where $m$ is the quantity of linear segments in the piecewise function (Wang et al., 2013). Figure 2 shows a few instances of piecewise linear secant approximations with various quantities of linear segments $(m=1,3,5,10)$ for the non-linear bunker consumption function $G(y)=0.012(y)^{-2} / 24$. Lower and upper bounds on vessel sailing speed were set to $v^{\min }=15$ knots to $v^{\max }=25 \mathrm{knots}$, respectively (i.e. $0.040 \leq y \leq 0.067$ ). It can be observed that increasing quantity of linear segments $m$ enhances the accuracy of approximation for $G(y)$.

Let $K=\{1,2, \ldots . m\}$ be the set of linear segments in the piecewise function $\overline{G_{m}}(y)$. Let $b_{i k}=1$ if linear segment $k$ is chosen to approximate the bunker consumption function at 

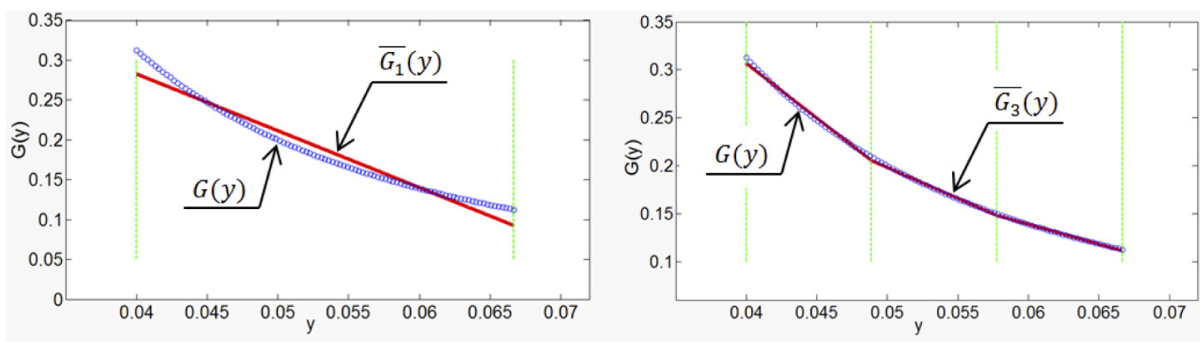

\section{Enforcing emission restrictions}
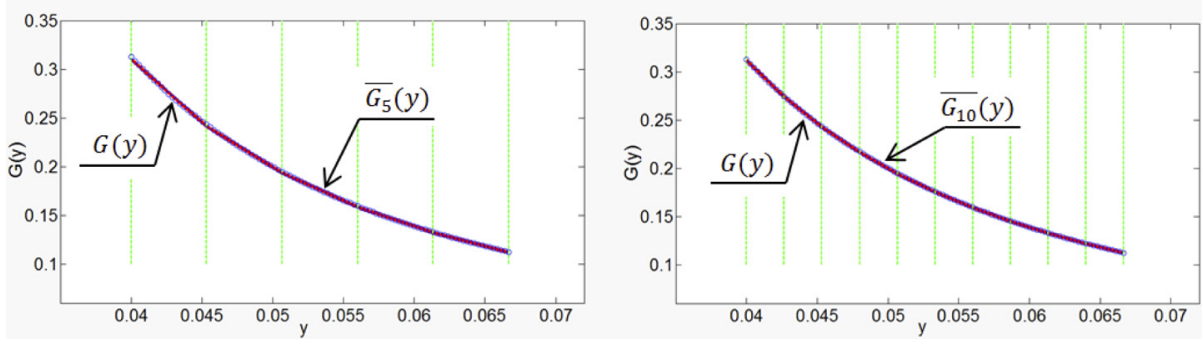

Figure 2.

Bunker consumption function linear approximations

voyage leg $i$ (0 otherwise). Denote $s t_{k}, e d_{k}, k \in K$ as the speed reciprocal values at the start and the end (respectively) of linear segment $k$; $S L_{k}, I N_{k}, k \in K$ as the slope and the intercept of linear segment $k$; and $M_{1}, M_{2}$ as sufficiently large positive numbers. Then, $G V S P 1$ and $G V S P 2$ can be reformulated as linear problems (that will be referred to as $G V S P L 1$ and $G V S P L 2$, respectively) as follows:

\section{GVSPL1}

$$
\min \left[c^{O C} q+\sum_{i \in I}\left(\beta_{i} l_{i} \sum_{k \in K} \overline{G_{k}}\left(y_{i}\right)\right)+\sum_{i \in I} \sum_{s \in S_{i}} t c_{i s} x_{i s}+\sum_{i \in I} c_{i}^{L T} l t_{i}+\mu \sum_{i \in I} t_{i} N C T_{i}\right]
$$

subject to:

Constraints sets (6), (8)-(16), (18)-(20).

$$
\begin{gathered}
\sum_{k \in K} b_{i k}=1 \forall i \in I \\
s t_{k} b_{i k} \leq y_{i} \forall i \in I, k \in K \\
e d_{k}+M_{1}\left(1-b_{i k}\right) \geq y_{i} \forall i \in I, k \in K \\
\overline{G_{k}}\left(y_{i}\right) \geq S L_{k} y_{i}+I N_{k}-M_{2}\left(1-b_{i k}\right) \forall i \in I, k \in K \\
t_{i}=l_{i} y_{i} \forall i \in I
\end{gathered}
$$

and

$$
1 / v^{\text {max }} \leq y_{i} \leq 1 / v^{\text {min }} \forall i \in I
$$


MABR

1,2

Constraints set (25) indicates that only one linear segment $k$ will be chosen to approximate the bunker consumption function at voyage leg $i$. Constraints sets (26) and (27) define the range of values for the vessel sailing speed reciprocal, when linear segment $k$ is chosen to approximate the bunker consumption function at voyage leg $i$. Constraints set (28) calculates the approximated bunker consumption value at voyage leg $i$. Constraints set (29) estimates the sailing time of a vessel between consequent ports $i$ and $i+1$. Constraints set (30) establishes bounds on sailing speed of a vessel at voyage leg $i$. Strict lower bounds for $M_{1}$ and $M_{2}$ can be defined as follows: $M_{1}=1 / v^{\text {min }}, M_{2}=$ $S L_{1}\left(1 / v^{\max }\right)+I N_{1}$. Note that parameters $M_{1}$ and $M_{2}$ in constraints sets (27) and (28) can be substituted with $M=\max \left\{M_{1} ; M_{2}\right\}$.

\section{GVSPL2}

$$
\min \left[c^{O C} q+\sum_{i \in I}\left(\beta_{i} l_{i} \sum_{k \in K} \overline{G_{k}}\left(y_{i}\right)\right)+\sum_{i \in I} \sum_{s \in S_{i}} t c_{i s} x_{i s}+\sum_{i \in I} c_{i}^{L T} l t_{i}+\mu \sum_{i \in I} t_{i} N C T_{i}\right]
$$

subject to:

Constraints sets (6), (8)-(16), (18)-(20), (23), (25)-(30).

$$
S O_{2 i}=0.02 P_{i} l_{i} \sum_{k \in K} \bar{G}_{k}\left(y_{i}\right) \forall i \in I
$$

In $G$ VSPL2, objective function (31) aims to minimize the total route service cost. Constraints set (32) calculates $\mathrm{SO}_{2}$ emissions at voyage leg $i$.

There are two types of the secant approximations (Wang et al., 2013):

(1) the static secant approximation, $\mathbf{S S A}$; and

(2) the dynamic secant approximation, $D S A$.

If $\mathbf{S S A}$ is used, the quantity of linear segments in the approximation is fixed, and $G V S P L 1$ and $G V S P L 2$ should be solved only once. If $D S A$ is used, the quantity of linear segments in the approximation is a variable, and GVSPL1 and GVSPL2 should be solved iteratively by increasing the quantity of segments until the desired solution accuracy is achieved. The advantage of SSA is that GVSPL1 and GVSPL2 should be solved only once; however, if a large quantity of segments is used, the computational time may be significant. This study will use $D S A$ to solve GVSPL1 and GVSPL2. The main DSA steps are outlined in Procedure 1 for $G$ VSPL1. Note that similar steps were performed to solve $G \boldsymbol{V S P L 2}$. In Step 1, the initial quantity of segments in the approximation is set to $m=0$ and the initial accuracy is set to $\Delta=100$. Note that the initial accuracy can be set to any number greater than the target accuracy (i.e. $\Delta>\Delta_{t}$ ). Then, $\boldsymbol{D S} A$ enters the loop, where in Step 3, one segment is added to the approximation. Then, in Step 4, GVSPL1 with the updated quantity of segments is solved, and a new vessel schedule $V S$ and the associated objective function value $Z$ are obtained. In Step 5, function $\boldsymbol{E s t O b j}$ (InputData, VS) estimates the true value of the objective function $Z^{*}$ (i.e. value of the non-linear objective function at the solution $V S$, provided by $G V S P L 1)$. In Step 6, the solution accuracy is updated. $\boldsymbol{D S} \boldsymbol{A}$ terminates when the target accuracy of 
GVSPL1 solution is achieved. Performance of $D S A$ will be evaluated against $S S A$ in the numerical experiments section.

\section{Enforcing emission restrictions}

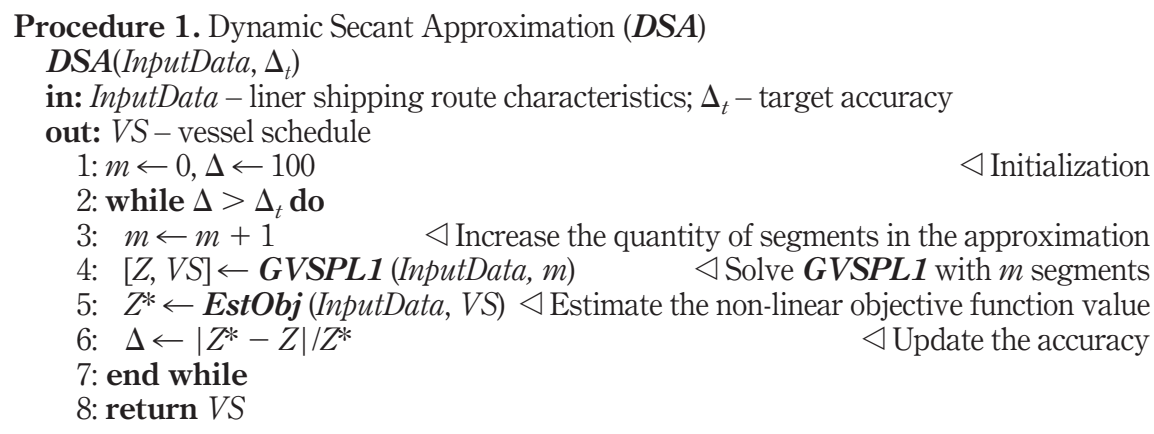

\section{Numerical experiments}

This section presents numerical experiments that were undertaken to evaluate the performance of the proposed solution approach and assess advantages and disadvantages from enforcing emission restrictions within ECAs.

\subsection{Input data description}

This study considers the French Asia Line 3 route (Figure 3), which is served by CMA CGM (2016) liner shipping company. This liner shipping route connects North Europe, Red Sea and Asia. The port rotation for the French Asia Line 3 route includes 13 ports of call (the distances between consequent ports in nautical miles are shown in parenthesis and were retrieved from the world seaports catalogue[1]), where the Port of Kelang (Malaysia) and Port of Le Havre (France) are visited twice:

1. Rotterdam, NL (341) $\rightarrow 2$. Hamburg, DE (426) $\rightarrow 3$. Antwerp, BE (244) $\rightarrow$ 4. Le Havre, FR $(4,403) \rightarrow 5$. Jeddah, SA $(4,455) \rightarrow 6$. Port Kelang, MY $(2,835) \rightarrow 7$. Ningbo, CN $(87) \rightarrow 8$. Shanghai, CN (606) $\rightarrow$ 9. Xiamen, CN (731) $\rightarrow 10$. Chiwan, CN (395) $\rightarrow 11$. Yantian, CN (2,045) $\rightarrow$ 12. Port Kelang, MY $(8,857) \rightarrow 13$. Le Havre, FR (355) $\rightarrow 1$. Rotterdam, NL.

The available liner shipping literature (Wang and Meng, 2012a, 2012b, 2012c; Zampelli et al., 2014; OOCL, 2016; World Shipping Council, 2016, etc.) was used to

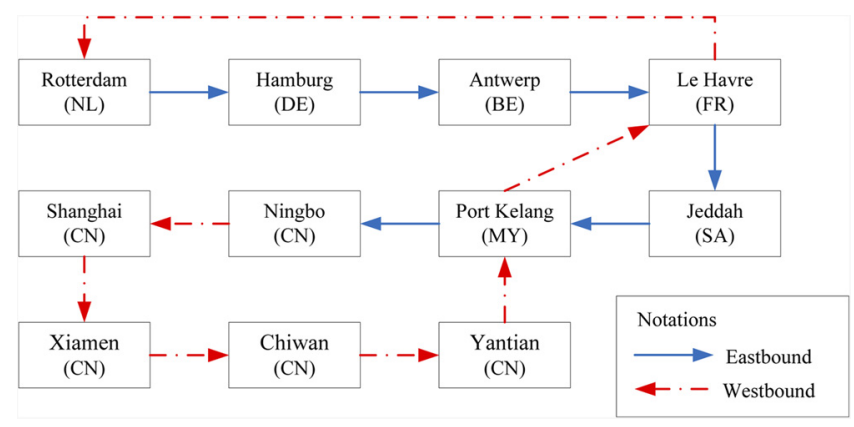

Figure 3.

The French Asia Line 3 route 
MABR

1,2

generate the numerical data necessary for computational experiments (Table I). The end of TW at each port of the port rotation was estimated using the end of TW at preceding port, length of a voyage leg between consequent ports and bounds of the vessel sailing speed: $t w_{i+1}^{e}=t w_{i}^{e}+l_{i} / U\left[v^{\min } ; v^{\max }\right] \forall i \in I$, where $U$ is a notation for uniformly distributed pseudorandom numbers. The quantity of containers, transported at voyage leg $i$ was generated as $N C T_{i}=U[5,000 ; 8,000] \forall i \in I$ TEUs.

The weekly container demand $N C_{i}$ at large ports of the port rotation was assigned as $U[500 ; 2,000]$ TEUs. Note that a given port was considered as a "large port" only if it belonged to the list of top 20 world container ports based on the overall throughput (World Shipping Council, 2016). The weekly container demand at smaller ports was generated as $U[200 ; 1,000]$ TEUs. This study assumes that the following handling productivities $\left(d_{i s}\right)$ were offered to the liner shipping company at large ports: $[125 ; 100 ; 75 ; 50] \mathrm{TEUs} / \mathrm{h}$. At smaller ports, the liner shipping company was able to request $[100 ; 75 ; 60 ; 50] \mathrm{TEUs} / \mathrm{h}$ or $[75 ; 70 ; 60 ; 50] \mathrm{TEUs} / \mathrm{h}$. The assumption regarding the handling productivities can be justified by the fact that marine container terminal operators at large ports typically have more equipment available for serving vessels and, hence, are able to provide more handling rate alternatives to the liner shipping company. In the meantime, increasing quantity of TEUs handled may increase productivity.

Based on the established IMO regulations, the North Sea and the English Channel were designated as $\mathrm{SO}_{\mathrm{x}}$ ECAs for the considered liner shipping route (IMO, 2016a). The restrictions on quantity of $\mathrm{SO}_{2}$ emissions produced at voyage legs passing through ECAs were assigned as follows: $R S O_{2 i}=0.02 P_{i} \gamma l_{i}\left(U\left[v^{\min } ; v^{\max }\right]\right)^{\alpha-1} / 24 \forall i \in I^{*}$ tons. The vessel handling cost per TEU $s c_{i s}$ at port $i$ under handling rate $s$ was estimated as:

\begin{tabular}{|c|c|c|}
\hline Parameter & Value & Source(s) \\
\hline Bunker consumption coefficients: $\alpha, \gamma$ & $\begin{array}{l}\alpha=3 \\
\gamma=0.012\end{array}$ & $\begin{array}{l}\text { Du et al. (2011), Wang and Meng (2012b), } \\
\text { Psaraftis and Kontovas (2013) }\end{array}$ \\
\hline Unit HFO cost: $\beta_{H F O}(\mathrm{USD} /$ ton$)$ & 300 & Fagerholt and Psaraftis (2015) \\
\hline Unit MGO cost: $\beta_{M G O}$ (USD/ton) & 600 & Fagerholt and Psaraftis (2015) \\
\hline $\begin{array}{l}\text { Weekly operational cost of a vessel: } \\
c^{O C} \text { (USD/week) }\end{array}$ & 300,000 & $\begin{array}{l}\text { Wang and Meng (2012a, 2012b, 2012c) } \\
\text { Dulebenets }(2015,2016)\end{array}$ \\
\hline $\begin{array}{l}\text { Delayed arrival penalty: } c_{i}^{L T} \\
\text { (USD/hours) }\end{array}$ & $U[5,000 ; 10,000]$ & Zampelli et al. (2014) \\
\hline $\begin{array}{l}\text { Unit inventory cost: } \mu \text { (USD per TEU } \\
\text { per hour) }\end{array}$ & 1 & $\begin{array}{l}\text { Wang et al. (2014), Dulebenets et al. } \\
\text { (2015a) }\end{array}$ \\
\hline Percent of sulphur in MGO: $P_{M G O}(\%)$ & 0.1 & $\begin{array}{l}\text { Psaraftis and Kontovas (2013), Kontovas } \\
\text { (2014) }\end{array}$ \\
\hline Percent of sulphur in HFO: $P_{H F O}(\%)$ & 3.5 & $\begin{array}{l}\text { Psaraftis and Kontovas (2013), Kontovas } \\
\text { (2014) }\end{array}$ \\
\hline Duration of TW (hours) & $U[24 ; 72]$ & OOCL (2016) \\
\hline $\begin{array}{l}\text { Minimum sailing speed of a vessel: } \\
v^{\min } \text { (knots) }\end{array}$ & 15 & Wang and Meng (2012a, 2012b, 2012c) \\
\hline $\begin{array}{l}\text { Maximum sailing speed of a vessel: } \\
v^{\max } \text { (knots) }\end{array}$ & 25 & Wang and Meng (2012a, 2012b, 2012c) \\
\hline $\begin{array}{l}\text { Maximum quantity of deployed } \\
\text { vessels: } q^{\max }\end{array}$ & 15 & Wang and Meng (2012a, 2012b, 2012c) \\
\hline
\end{tabular}

Table I.

Numerical data vessels: $q^{\max }$ 
$s c_{i s}=m h c \pm U[0 ; 50] \forall i \in I, s \in S_{i} \mathrm{USD} / \mathrm{TEU}$, where $m h c$ is the mean handling cost. Then, the overall port handling cost was computed as: $t c_{i s}=s c_{i s} N C_{i} \forall i \in I, s \in S_{i}$ USD. The $m h c$ was set equal to $[700 ; 625 ; 550 ; 475]$ USD/TEU for four available handling rates, respectively (World Bank, 2016; The Port Authority of New York and New Jersey, 2016; Dulebenets et al., 2015b). This study also assumes that each marine container terminal operator perceives the vessel handling cost differently (i.e. vessel handling charge for the same handling rate varies from one port to the other). The latter aspect is captured for by the second (and random) term of the $s c_{i s}$ equation.

All numerical experiments were conducted on a Dell T1500 Intel(T) Core i5 Processor with 2.00 GB RAM. MATLAB (2014a) was used to develop the secant approximations for the bunker consumption function (Mathworks, 2016). $\boldsymbol{G} \boldsymbol{V S P L 1}$ and $\boldsymbol{G} \boldsymbol{V S P L 2}$ were solved using CPLEX of General Algebraic Modeling System at each iteration of $D S A$.

\subsection{Performance of the solution approach}

$\boldsymbol{D S} \boldsymbol{A}$ was compared against $\mathbf{S S A}$ with $m=100$ segments. A total of 20 instances were developed using the data, described in Section 6.1 and presented in Table I, by changing the service TWs at ports and TW duration. The target accuracy for $D S A$ was set to $\Delta_{t}=0.1 \% . G V S P L 1$ and $\boldsymbol{G V S P L 2}$ were solved using $\mathbf{S S A}$ and $\boldsymbol{D S} \boldsymbol{A}$ for each one of the generated instances, and results are presented in Table II, including the following information for $S S A$ and $D S A$ :

- instance number;

- quantity of linear segments $(m)$ used in the approximation to solve the problem;

- objective gap $\Delta=\rfloor\left(Z^{*}-Z\right) / Z^{*} \mid$, where $Z$ is $G V S P L 1 / G V S P L 2$ objective function value and $Z$ is value of the non-linear objective function at the solution, provided by $G V S P L 1 / G V S P L 2$; and

- average over five replications of CPU time.

For example, $\mathbf{S S A}$ required 100 linear segments to solve $\boldsymbol{G} \boldsymbol{V S P L 1}$ for problem instance I3 with the objective gap of $2.0 \mathrm{E}-14$ and computational time of $20.6 \mathrm{~s}$. For the same problem instance (I3), $\boldsymbol{D S} \boldsymbol{A}$ required five linear segments to solve $\boldsymbol{G V S P L 1}$ with the objective gap of $9.4 \mathrm{E}-04$ and computational time of $0.9 \mathrm{~s}$.

It can be observed that on average, over the considered problem instances, $\boldsymbol{D S} \boldsymbol{A}$ required five linear segments in the approximation to solve $G V S P L 1$ and $G V S P L 2$ with the target accuracy, which is significantly smaller as compared to the quantity of segments in $\mathbf{S S A}$. Objective gaps, produced by $\boldsymbol{D S} A$, were larger as compared to the ones produced by $\mathbf{S S A}$. The latter can be explained by the fact that $\mathbf{S S A}$ used much more segments for the bunker consumption function approximation. The average over five replications and 20 problem instances of $D S A C P U$ time comprised 0.9 and $0.8 \mathrm{~s}$ for GVSPL1 and GVSPL2, respectively. The average over five replications and 20 problem instances of $\mathbf{S S A}$ CPU time comprised 19.8 and $12.2 \mathrm{~s}$ for $\mathbf{G V S P L 1}$ and $G V S P L 2$, respectively. Results from the computational experiments demonstrate that $D S A$ was able to achieve the target accuracy within significantly smaller CPU time as compared to $\mathbf{S S A}$ for all generated problem instances, which indicates the efficiency of the proposed solution approach.

\subsection{Managerial insights}

The total route service cost and its components were estimated after obtaining the solutions for $G V S P L 1$ and $G V S P L 2$ for each one of the considered problem instances.
Enforcing emission

restrictions 


\begin{tabular}{|c|c|c|c|c|c|c|c|}
\hline \multirow[t]{2}{*}{$\begin{array}{l}\text { MABR } \\
1,2\end{array}$} & \multicolumn{3}{|c|}{$\begin{array}{c}\text { Quantity of } \\
\text { segments } \\
\text { GVSPL1/GVSPL2 }\end{array}$} & \multicolumn{2}{|c|}{ Objective gap $G V S P L 1 / G V S P L 2$} & \multicolumn{2}{|c|}{$\begin{array}{c}\text { CPU Time, } \mathrm{s} \\
\text { GVSPL1/GVSPL2 }\end{array}$} \\
\hline & Instance & SSA & $D S A$ & SSA & $D S A$ & $S S A$ & $D S A$ \\
\hline \multirow{18}{*}{124} & I1 & $100 / 100$ & $5 / 5$ & $2.0 \mathrm{E}-14 / 7.9 \mathrm{E}-08$ & $9.6 \mathrm{E}-04 / 5.6 \mathrm{E}-04$ & $20.4 / 12.2$ & $0.9 / 0.9$ \\
\hline & $\mathrm{I} 2$ & $100 / 100$ & $5 / 5$ & $1.9 \mathrm{E}-14 / 7.2 \mathrm{E}-08$ & $9.0 \mathrm{E}-04 / 5.3 \mathrm{E}-04$ & $18.2 / 11.7$ & $0.9 / 0.9$ \\
\hline & I3 & $100 / 100$ & $5 / 4$ & $2.0 \mathrm{E}-14 / 8.0 \mathrm{E}-08$ & $9.4 \mathrm{E}-04 / 9.7 \mathrm{E}-04$ & $20.6 / 12.4$ & $0.9 / 0.6$ \\
\hline & $\mathrm{I} 4$ & $100 / 100$ & $5 / 4$ & $1.9 \mathrm{E}-14 / 7.5 \mathrm{E}-08$ & $8.9 \mathrm{E}-04 / 9.5 \mathrm{E}-04$ & 20.1/11.6 & $1.0 / 0.6$ \\
\hline & I5 & $100 / 100$ & $5 / 5$ & $2.0 \mathrm{E}-14 / 7.4 \mathrm{E}-08$ & $9.3 \mathrm{E}-04 / 5.9 \mathrm{E}-04$ & $17.4 / 12.4$ & $0.9 / 0.9$ \\
\hline & I6 & $100 / 100$ & $5 / 5$ & $1.9 \mathrm{E}-14 / 7.7 \mathrm{E}-08$ & $8.7 \mathrm{E}-04 / 4.8 \mathrm{E}-04$ & $20.3 / 12.3$ & $0.9 / 0.9$ \\
\hline & I7 & $100 / 100$ & $5 / 4$ & $2.0 \mathrm{E}-14 / 7.8 \mathrm{E}-08$ & $9.2 \mathrm{E}-04 / 9.9 \mathrm{E}-04$ & $20.5 / 12.4$ & $0.9 / 0.6$ \\
\hline & I8 & $100 / 100$ & $5 / 5$ & $2.0 \mathrm{E}-14 / 7.7 \mathrm{E}-08$ & $9.1 \mathrm{E}-04 / 6.9 \mathrm{E}-04$ & $20.4 / 12.3$ & $0.9 / 0.9$ \\
\hline & I9 & $100 / 100$ & $5 / 5$ & $2.0 \mathrm{E}-14 / 8.1 \mathrm{E}-08$ & $9.0 \mathrm{E}-04 / 6.8 \mathrm{E}-04$ & 20.4/12.3 & $0.9 / 0.9$ \\
\hline & $\mathrm{I} 10$ & $100 / 100$ & $5 / 4$ & $2.0 \mathrm{E}-14 / 8.0 \mathrm{E}-08$ & $8.5 \mathrm{E}-04 / 9.6 \mathrm{E}-04$ & 20.7/12.4 & $0.9 / 0.6$ \\
\hline & I11 & $100 / 100$ & $5 / 5$ & $1.9 \mathrm{E}-14 / 7.0 \mathrm{E}-08$ & $8.9 \mathrm{E}-04 / 5.7 \mathrm{E}-04$ & $17.6 / 11.8$ & $0.9 / 0.9$ \\
\hline & $\mathrm{I} 12$ & $100 / 100$ & $5 / 5$ & $1.9 \mathrm{E}-14 / 7.5 \mathrm{E}-08$ & $9.3 \mathrm{E}-04 / 6.0 \mathrm{E}-04$ & $17.9 / 12.2$ & $0.9 / 0.9$ \\
\hline & $\mathrm{I} 13$ & $100 / 100$ & $5 / 4$ & $2.0 \mathrm{E}-14 / 8.1 \mathrm{E}-08$ & $9.1 \mathrm{E}-04 / 9.4 \mathrm{E}-04$ & $20.6 / 12.4$ & $0.9 / 0.6$ \\
\hline & $\mathrm{I} 14$ & $100 / 100$ & $5 / 5$ & $2.0 \mathrm{E}-14 / 8.1 \mathrm{E}-08$ & $9.3 \mathrm{E}-04 / 5.9 \mathrm{E}-04$ & $20.5 / 12.4$ & $0.9 / 0.9$ \\
\hline & I15 & $100 / 100$ & $5 / 5$ & $2.0 \mathrm{E}-14 / 7.8 \mathrm{E}-08$ & $8.9 \mathrm{E}-04 / 4.8 \mathrm{E}-04$ & $20.4 / 12.3$ & $0.9 / 0.9$ \\
\hline & $\mathrm{I} 16$ & $100 / 100$ & $5 / 5$ & $2.0 \mathrm{E}-14 / 8.1 \mathrm{E}-08$ & $9.2 \mathrm{E}-04 / 5.4 \mathrm{E}-04$ & 20.4/12.4 & $0.9 / 0.9$ \\
\hline & $\mathrm{I} 17$ & $100 / 100$ & $5 / 4$ & $2.0 \mathrm{E}-14 / 8.1 \mathrm{E}-08$ & $8.6 \mathrm{E}-04 / 9.4 \mathrm{E}-04$ & $20.5 / 12.4$ & $0.9 / 0.6$ \\
\hline & $\mathrm{I} 18$ & $100 / 100$ & $5 / 5$ & $1.9 \mathrm{E}-14 / 7.1 \mathrm{E}-08$ & $9.0 \mathrm{E}-04 / 5.8 \mathrm{E}-04$ & $18.3 / 11.4$ & $0.9 / 0.9$ \\
\hline Table II. & I19 & $100 / 100$ & $5 / 4$ & $2.0 \mathrm{E}-14 / 8.1 \mathrm{E}-08$ & $9.4 \mathrm{E}-04 / 9.1 \mathrm{E}-04$ & 20.6/12.4 & $0.9 / 0.5$ \\
\hline Performance of the & $\mathrm{I} 20$ & $100 / 100$ & $5 / 4$ & $2.0 \mathrm{E}-14 / 7.8 \mathrm{E}-08$ & $9.1 \mathrm{E}-04 / 9.4 \mathrm{E}-04$ & 20.5/12.3 & $0.9 / 0.6$ \\
\hline solution approach & Average: & $100 / 100$ & $5.0 / 4.6$ & $2.0 \mathrm{E}-14 / 7.7 \mathrm{E}-08$ & $9.1 \mathrm{E}-04 / 7.2 \mathrm{E}-04$ & $19.8 / 12.2$ & $0.9 / 0.8$ \\
\hline
\end{tabular}

Results are presented in Figure 4, including the following cost components: the total route service cost, $Z$; the total weekly vessel operational cost, $O C$; the total bunker consumption cost, $B C$; the total port handling cost, $P C$; the total late arrival penalty, $L P$; and the total inventory cost, $I C$.

We observe that all route service cost components, except the bunker consumption cost, are greater (or equal in some instances) for GVSPL2 vessel schedules, as compared to $G V S P L 1$ vessel schedules. The restrictions on the quantity of emissions produced within ECAs decrease the bunker consumption cost (i.e. the vessel sailing speed is reduced to comply with the emission restrictions at voyage legs passing through ECAs) for vessel schedules provided by $G$ VSPL2. Moreover, port handling costs are higher for $\mathbf{G V S P L 2}$ vessel schedules as compared to $G V S P L 1$ vessel schedules. The latter can be explained by the fact that introduction of emission restrictions would require the liner shipping company to select handling rates with a higher productivity to save time in ports. Savings in port times can be further used by the liner shipping company to increase the vessel sailing time within ECAs (i.e. sail at a lower speed to the consequent port of the port rotation and reduce the quantity of emissions produced within ECAs).

GVSPL2 produces vessel schedules with the late arrival penalty, which is substantially higher as compared to the late arrival penalty associated with $G V S P L 1$ vessel schedules. Increase in the late arrival penalty for GVSPL2 vessel schedules indicates that the liner shipping company may have to violate the port arrival TWs, 


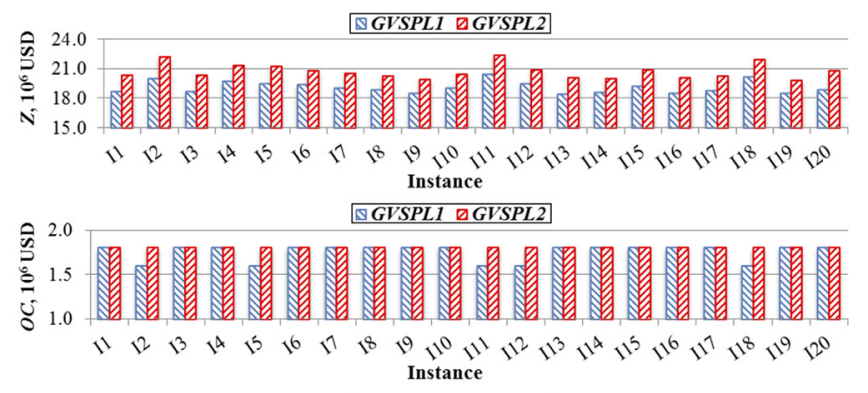

\section{Enforcing emission restrictions}
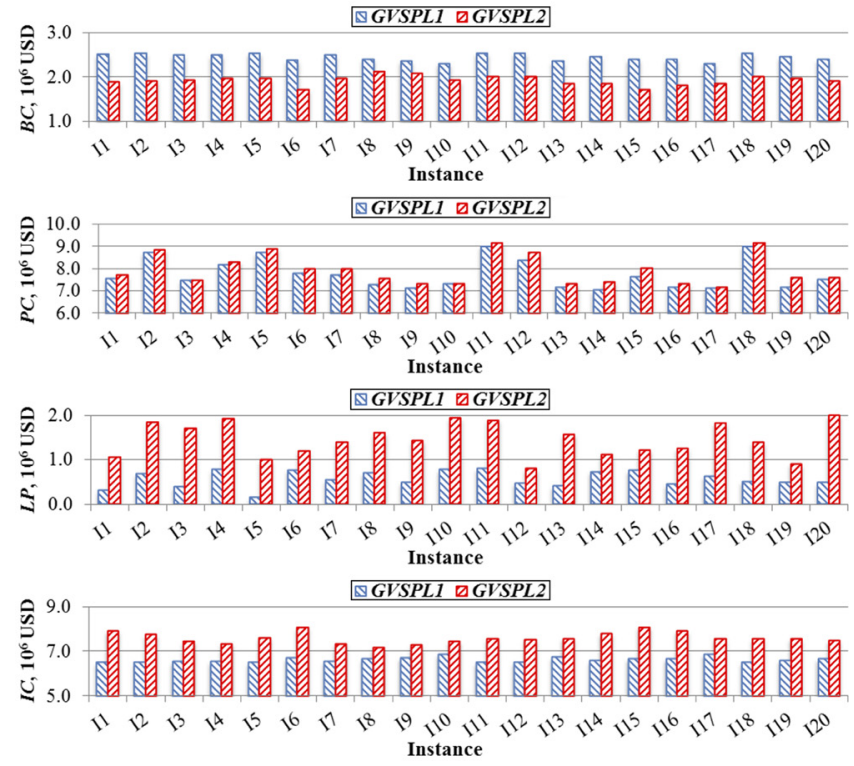

Figure 4.

Values of the objective function and its components:

GVSPL1 vs GVSPL2

negotiated with marine container terminal operators, to meet the restrictions on the quantity of emissions produced within ECAs. Because of increasing vessel sailing time, the total inventory cost is higher for vessel schedules, suggested by GVSPL2, as compared to GVSPL1 vessel schedules. Furthermore, GVSPL2 vessel schedules have higher vessel weekly operational cost for certain instances (i.e. I2, I5, I11, etc.). The latter can be explained by the fact that increase in sailing time for $G V$ SPL2 schedules requires deployment of more vessels at the given liner shipping route to guarantee the weekly service at each port of the port rotation. It was found that on average, over all considered problem instances, the total route service cost could increase by 7.8 per cent from introducing restrictions on the quantity of $\mathrm{SO}_{2}$ emissions produced within ECAs. A detailed comparison of $G V S P L 1$ and $G V S P L 2$ vessel schedules in terms of sailing speed selection within ECAs, bunker consumption, emissions produced within ECAs and port late arrivals is presented next.

6.3.1 Vessel sailing speed selection within Emission Control Areas. The vessel sailing speeds were retrieved for GVSPL1 and GVSPL2 schedules for each one of the considered problem instances at three voyage legs passing through ECAs: 
MABR

1,2

126

(1) voyage leg 1: Rotterdam (NL) to Hamburg (DE);

(2) voyage leg 2: Hamburg (DE) to Antwerp (BE); and

(3) voyage leg 3: Antwerp (BE) to Le Havre (FR).

The average vessel sailing speeds (in knots) over the generated problem instances at voyage legs 1-3 are presented in Figure 5 for GVSPL1 and GVSPL2 vessel schedules. Notation $v_{i}^{1}$ was adopted for the vessel sailing speed at voyage leg $i$ suggested by $\boldsymbol{G} V \mathbf{S P L 1}$, whereas notation $v_{i}^{2}$ was adopted for the vessel sailing speed at voyage leg $i$ suggested by $G \boldsymbol{V S P L 2}$. We observe that on average, the vessel sailing speed was reduced by 33.3, 26.5 and 10.0 per cent at voyage legs 1-3, passing through ECAs, when emission restrictions were imposed. Reduction in the vessel sailing speed increases the container transit time through ECAs but decreases the quantity of $\mathrm{SO}_{2}$ emissions produced.

6.3.2 Bunker consumption comparison. Vessel schedules, produced by GVSPL1 and $G V S P L 2$, were compared in terms of the amount of fuel (both HFO and MGO) consumed by vessels serving the French Asia Line 3 route. As GVSPL2 vessel schedules have lower bunker consumption costs (Section 6.3 and Figure 4) as compared to $\boldsymbol{G V S P L 1}$ vessel schedules, the total bunker consumption was also found to be lower for all the considered problem instances. Furthermore, numerical experiments demonstrate that $\mathbf{G} \boldsymbol{V S P L 2}$ vessel schedules not only required less MGO at voyage legs, passing through ECAs, but also yielded HFO savings. The bunker consumption savings were estimated for all generated problem instances, and results are presented in Figure 6 for HFO and MGO fuel types. We observe that on average, GVSPL2 vessel schedules require 19.6 per cent less HFO and 40.4 per cent less MGO. The MGO savings can be explained by the fact that the liner shipping company was required to decrease the vessel sailing speed (hence, reduce the MGO consumption) at voyage legs, passing through ECAs, to avoid violation of the emission restrictions. In the meantime, introduction of emission restrictions reduced vessel sailing speeds not only within ECAs but also at the adjacent voyage legs, which yielded the HFO consumption savings.

Figure 5.

Average vessel sailing speeds within ECAs: $G V S P L 1$ vs GVSPL2

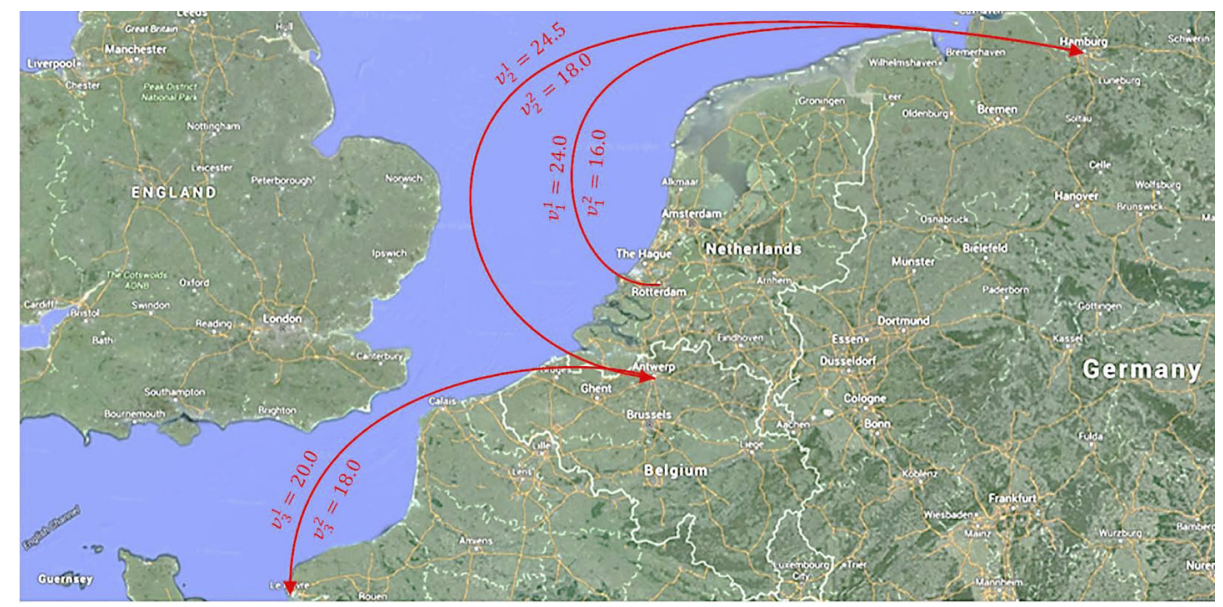




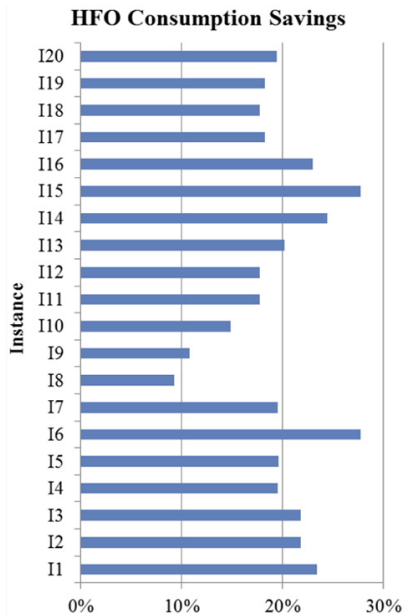

(a)

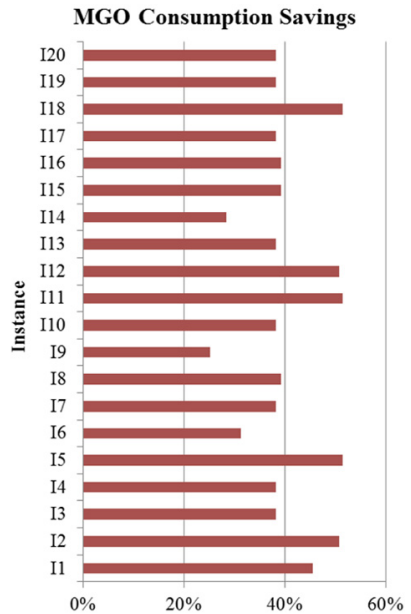

(b)

Notes: (a) HFO consumption savings; (b) MGO consumptions, \%

6.3.3 Emission comparison. The total quantity of $\mathrm{SO}_{2}$ emissions was calculated for GVSPL1 and GVSPL2 vessel schedules at voyage legs within ECAs for all the considered problem instances, and results are presented in Figure 7. Numerical experiments showcase that introduction of emission restrictions at voyage legs, passing through ECAs, in $\boldsymbol{G V S P L 2}$ vessel schedules reduced the quantity of $\mathrm{SO}_{2}$ emissions by 40.4 per cent (i.e. proportional to the MGO consumption savings). We observe that on average, $\boldsymbol{G} \boldsymbol{V S P} \boldsymbol{P} \boldsymbol{1}$ vessel schedules produced $7.2 \mathrm{~kg}$ of $\mathrm{SO}_{2}$, whereas $\boldsymbol{G} \boldsymbol{V S P L} 2$ vessel schedules produced $4.2 \mathrm{~kg}$ of $\mathrm{SO}_{2}$. Hence, enforcing emission restrictions within ECAs can significantly reduce the pollution levels.

6.3.4 Port late arrivals. The hours of late arrivals at ports of call were estimated for $G V S P L 1$ and $G V S P L 2$ vessel schedules for all 20 problem instances, and the average values are shown in Figure 8 for each port of call. As GVSPL2 vessel schedules have higher late arrival penalties (Section 6.3 and Figure 4) as compared to $G V S P L 1$ vessel schedules, the hours of late vessel arrivals to ports of call were also found to be higher for all the considered problem instances. The increase in

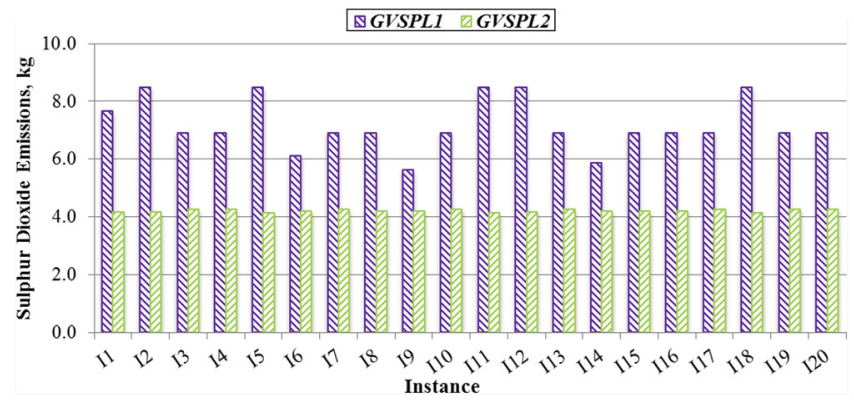

Figure 7.

Emissions produced within ECAs:

GVSPL1 vs GVSPL2 
MABR

1,2

128

hours of late arrivals for $\boldsymbol{G V S P L 2}$ vessel schedules as compared to $\boldsymbol{G V S P L 1}$ vessel schedules was recorded not only at ports located within ECAs (i.e. Rotterdam, NL; Hamburg, DE; Antwerp, BE; and Le Havre, FR) but also at ports located outside ECAs (e.g. Yantian, CN; Port Kelang, MY; etc.). Hence, introduction of emission restrictions required the liner shipping company to make significant changes in the vessel schedule. Results from computational experiments indicate that the hours of port late arrivals may increase on average by 152.8 per cent from imposing the emission restrictions within ECAs.

\subsection{Discussion}

This study proposes two mathematical models for the green vessel scheduling problem in a liner shipping route with ECAs. The first mathematical model captures the existing IMO regulations, whereas the second one complies not only with the established IMO requirements within ECAs but also enforces restrictions on the actual quantity of emissions produced. Numerical experiments, performed for the French Asia Line 3 route, demonstrate that introduction of emission restrictions on average reduces the quantity of emissions produced by 40.4 per cent. Furthermore, emission restrictions will require the liner shipping company to decrease vessel sailing speeds within ECAs, which shall result in bunker consumption savings but an increase in the transit time of containers and, in turn, an increase in the total inventory cost. Increase in the transit time of containers (hence, increase in the total vessel turnaround time) may require deployment of more vessels to ensure the weekly service frequency at ports of call. It was found that the total vessel route service cost might increase by 7.8 per cent from imposing restrictions on the emissions produced within ECAs.

In conclusion, advantages from enforcing emission restrictions within ECAs can be summarized as follows:

- reduction in the quantity of emissions produced;

- improving the environmental sustainability;

- reduction in the bunker consumption (both MGO and HFO fuel types); and

- reduction in the total bunker consumption cost.

The list of disadvantages from enforcing emission restrictions within ECAs includes the following:

Figure 8.

Port late arrivals:

GVSPL1 vs GVSPL2
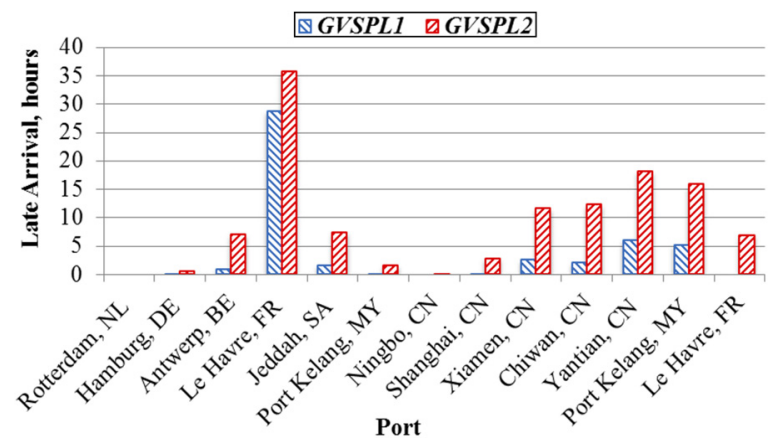
- increase in the total weekly vessel operational cost;

- increase in the total port handling cost;

- potential late vessel arrivals to ports of call;

- increase in the total transit time of containers and associated inventory costs; and

- increase in the total route service cost.

\section{Conclusions and future research}

Considering a rapidly growing attention of the community to the environmental concerns, liner shipping companies should implement new strategies for developing their vessel schedules and improving environmental sustainability. The existing environmental regulations in liner shipping do not enforce any restrictions on the actual quantity of emissions that could be produced within ECAs. This study performed a comprehensive assessment of advantages and disadvantages from enforcing emission restrictions within ECAs. Two mixed-integer non-linear mathematical models were developed to achieve the latter objective. The first program modeled the existing IMO regulations, whereas the second one along with the established IMO requirements also enforced restrictions on the quantity of emissions produced within the ECAs. The objective of both models was to minimize the total route service cost. The original models were linearized and solved using the dynamic secant approximation procedure. Numerical experiments were conducted for the French Asia Line 3 route, served by CMA CGM liner shipping company and passing through ECAs with $\mathrm{SO}_{\mathrm{x}}$ control.

Results demonstrated that the proposed solution approach outperformed the static secant approximation procedure and was able to achieve the target accuracy within a significantly smaller computational time. Furthermore, introduction of emission restrictions reduced the quantity of $\mathrm{SO}_{2}$ emissions produced by 40.4 per cent. In the meantime, emission restrictions required the liner shipping company to decrease the vessel sailing speed not only at voyage legs within ECAs but also at the adjacent voyage legs, which increased the total vessel turnaround time and in turn increased the total route service cost by 7.8 per cent. The developed mathematical model can serve as an efficient practical tool for liner shipping companies in developing green vessel schedules, enhancing energy efficiency and improving environmental sustainability. The future research may consider the following extensions:

- implement the developed mathematical models for various liner shipping routes;

- consider heterogeneous vessel fleet (i.e. vessels, serving a given liner shipping route, have different technical characteristics);

- account for uncertainty in bunker consumption; and

- account for uncertainty in port handling times.

\section{Note}

1. Available at: www.searates.com

\section{References}

Cariou, P. (2011), "Is slow steaming a sustainable means of reducing $\mathrm{CO}_{2}$ emissions from container shipping?", Transportation Research Part D, Vol. 16 No. 3, pp. 260-264. 
MABR

1,2

Cariou, P. and Cheaitou, A. (2012), "The effectiveness of a European speed limit versus an international bunker-levy to reduce $\mathrm{CO}_{2}$ emissions from container shipping", Transportation Research Part D, Vol. 17 No. 1, pp. 116-123.

Chang, C. and Wang, C. (2014), "Evaluating the effects of speed reduce for shipping costs and $\mathrm{CO}_{2}$ emission", Transportation Research Part D, Vol. 31 No. 1, pp. 110-115.

CMA CGM (2016), "French Asia Line 3", available at: www.cma-cgm.com/products-services/lineservices/flyer/FAL3 (accessed 10 February 2016).

Corbett, J., Wang, H. and Winebrake, J. (2009), “The effectiveness and costs of speed reductions on emissions from international shipping”, Transportation Research Part D, Vol. 14 No. 1, pp. 593-598.

Cullinane, K. and Bergqvist, R. (2014), "Emission control areas and their impact on maritime transport", Transportation Research Part D, Vol. 28 No. 1, pp. 1-5.

DieselNet (2016), "International: IMO marine engine regulations", available at: www.dieselnet. com/standards/inter/imo.php (accessed 20 May 2016).

Du, Y., Chen, Q., Quan, X., Long, L. and Fung, R. (2011), "Berth allocation considering fuel consumption and vessel emissions", Transportation Research Part E, Vol. 47 No. 6, pp. 1021-1037.

Dulebenets, M.A. (2015), "Models and solution algorithms for improving operations in marine transportation”, Dissertation, The University of Memphis, Memphis, May.

Dulebenets, M.A. (2016), “A new simulation model for a comprehensive evaluation of yard truck deployment strategies at marine container terminals”, Open Science Journal, Vol. 1 No. 3, pp. 1-28.

Dulebenets, M.A., Golias, M.M. and Mishra, S. (2015a), "The green vessel schedule design problem: consideration of emissions constraints", Energy Systems, pp. 1-23.

Dulebenets, M.A., Golias, M.M., Mishra, S. and Heaslet, W.C. (2015b), "Evaluation of the Floaterm concept at marine container terminals via simulation", Simulation Modelling Practice and Theory, Vol. 54, pp. 19-35.

Eyring, V., Isaksen, I., Berntsen, T., Collins, W., Corbett, J., Endresen, O., Grainger, R., Moldanova, J., Schlanger, H. and Stevenson, D. (2010), “Transport impacts on atmosphere and climate: shipping”, Atmospheric Environment, Vol. 44 No. 37, pp. 4735-4771.

Fagerholt, K., Gausel, N.T., Rakke, J.G. and Psaraftis, H. (2015), "Maritime routing and speed optimization with emission control areas", Transportation Research Part C, Vol. 52, pp. 57-73.

Fagerholt, K. and Psaraftis, H. (2015), "On two speed optimization problems for ships that sail in and out of emission control areas", Transportation Research Part D, Vol. 39 No. 1, pp. 56-64.

Heitmann, N. and Khalilian, S. (2011), “Accounting for carbon dioxide emissions from international shipping: burden sharing under different UNFCCC allocation options and regime scenarios", Marine Policy, Vol. 35 No. 1, pp. 682-691.

IMO (2014), "Prevention of GHG emissions from ships", Third IMO GHG Study 2014 - Final Report.

IMO (2016a), "Sulphur oxides (SOx) - Regulation 14", available at: www.imo.org (accessed 20 May 2016).

IMO (2016b), “Air pollution, energy efficiency and greenhouse gas emissions”, available at: www. imo.org (accessed 20 May 2016).

Kontovas, C. (2014), "The Green Ship Routing and Scheduling Problem (GSRSP): a conceptual approach", Transportation Research Part D, Vol. 31 No. 1, pp. 61-69. 
Lindstad, H., Asbjornslett, B. and Stromann, A. (2011), "Reductions in greenhouse gas emissions and cost by shipping at lower speeds", Energy Policy, Vol. 1 No. 1, pp. 3456-3464.

Mansouri, S., Lee, H. and Aluko, O. (2015), "Multi-objective decision support to enhance environmental sustainability in maritime shipping: a review and future directions", Transportation Research Part E, Vol. 78 No. 3, pp. 3-18.

Marine Urea (2014), "MARPOL regulation”, available at: http://marineurea.com/marpol-noxregulation/ (accessed 25 May 2016).

Mathworks (2016), "Release 2014a”, available at: www.mathworks.com/ (accessed 10 May 2016).

Meng, Q., Wang, S., Andersson, H. and Thun, K. (2014), "Containership routing and scheduling in liner shipping: overview and future research directions", Transportation Science, Vol. 48 No. 2, pp. 265-280.

Miola, A. and Ciuffo, B. (2011), "Estimating air emissions from ships: meta-analysis of modelling approaches and available data sources", Atmospheric Environment, Vol. 45 No. 13, pp. 2242-2251.

OOCL (2016), "e-Services, sailing schedule, schedule by service loops, Asia-Europe (AET)", available at: www.oocl.com (accessed 10 February 2016).

Psaraftis, H. (2012), "Market-based measures for greenhouse gas emissions from ships: a review", WMU Journal of Maritime Affairs, Vol. 11 No. 1, pp. 211-232.

Psaraftis, H. and Kontovas, C. (2009), " $\mathrm{CO}_{2}$ emission statistics for the world commercial fleet", WMU Journal of Maritime Affairs, Vol. 8 No. 1, pp. 1-25.

Psaraftis, H. and Kontovas, C. (2010), "Balancing the economic and environmental performance of maritime transportation”, Transportation Research Part D, Vol. 15 No. 1, pp. 458-462.

Psaraftis, H. and Kontovas, C. (2013), "Speed models for energy-efficient maritime transportation: a taxonomy and survey", Transportation Research Part C, Vol. 26 No. 26, pp. 331-351.

Psaraftis, H. and Kontovas, C. (2014), "Ship speed optimization: concepts, models and combined speed-routing scenarios", Transportation Research Part C, Vol. 44 No. 1, pp. 52-69.

Qi, X. and Song, D. (2012), "Minimizing fuel emissions by optimizing vessel schedules in liner shipping with uncertain port times", Transportation Research Part E, Vol. 48 No. 4, pp. 863-880.

Song, D., Li, D. and Drake, P. (2015), "Multi-objective optimization for planning liner shipping service with uncertain port times", Transportation Research Part E, Vol. 84 No. 3, pp. 1-22.

The European Union (2016), "EU action on climate", available at: http://ec.europa.eu/clima/ policies/brief/eu/ (accessed 20 May 2016).

The Port Authority of New York and New Jersey (2016), "Marine terminal tariffs", available at: www.panynj.gov/port/tariffs.html (accessed 10 May 2016).

UNCTAD (2015), "Review of maritime transport", United Nations Conference on Trade and Development, New York, NY and Geneva.

Wang, S. and Alharbi, A. and Davy, P. (2014), "Liner ship route schedule design with port time windows", Transportation Research Part C, Vol. 41 No. 1, pp. 1-17.

Wang, S. and Meng, Q. (2012a), "Liner ship route schedule design with sea contingency time and port time uncertainty", Transportation Research Part B, Vol. 46 No. 5, pp. 615-633.

Wang, S. and Meng, Q. (2012b), "Sailing speed optimization for container ships in a liner shipping network", Transportation Research Part E, Vol. 48 No. 5, pp. 701-714.

Wang, S. and Meng, Q. (2012c), "Robust schedule design for liner shipping services", Transportation Research Part E, Vol. 48 No. 6, pp. 1093-1106. 
MABR

1,2
Wang, S., Meng, Q. and Liu, Z. (2013), "Bunker consumption optimization methods in shipping: a critical review and extensions", Transportation Research Part E, Vol. 53, pp. 49-62.

World Bank (2016), “Cost to import (US\$ per container)”, available at: http://data.worldbank.org/ indicator/IC.IMP.COST.CD (accessed 10 May 2016).

World Shipping Council (2016), “Top 50 world container ports”, available at: www.worldshipping. org (accessed 10 May 2016).

Zampelli, S., Vergados, Y., Schaeren, R., Dullaert, W. and Raa, B. (2014), “The berth allocation and quay crane assignment problem using a CP approach", Principles and Practice of Constraint Programming, Springer, Berlin Heidelberg, pp. 880-896.

\section{Corresponding author}

Maxim A. Dulebenets can be contacted at: mdulebenets@fsu.edu

For instructions on how to order reprints of this article, please visit our website: www.emeraldgrouppublishing.com/licensing/reprints.htm Or contact us for further details: permissions@emeraldinsight.com 